\begin{tabular}{c} 
International Journal of Advanced Chemistry, 2(2) (2014) 162-165 \\
International Journal of Advanced Chemistry \\
Journal home page: $\begin{array}{c}\text { www.sciencepubco.com/index.php/IJAC } \\
\text { doi: } 10.14419 / \text { ijac. } 22 \text { (2.3213 } \\
\text { Research Paper }\end{array}$ \\
\hline
\end{tabular}

\title{
Spectrophotometric determination of the stability constant of vanadium(v)-p-chloro-N-phenyl-p-chlorobenzo- hydroxamic acid complex
}

\author{
M. J. A. Abualreish ${ }^{1,2 *}$, A.M.Al msiedeen ${ }^{1}$ \\ ${ }^{1}$ Department of Chemistry, Faculty of Science, Northern Border University, Arar, Kingdom of Saudi Arabia (current address) \\ ${ }^{2}$ Department of Chemistry, Faculty of Science and Technology, Omdurman Islamic University, Sudan (permanent address) \\ *Corresponding author E-mail: Mustjeed_2008@hotmail.com
}

\begin{abstract}
The stability constant of the complex vanadium(v) p-chloro-N-Phenyl-p-chlorobenzohydroxamic acid was determined spectrophotometrically. The ligand p-chloro-N-phenyl-p-chloro-benzohydroxamic acid abbreviated in this paper as PCNPPCBHA was synthesized by the coupling of equimolar solutions of p-chlorobenzoyl chloride and freshly prepared p-chloro-ß-phenyl hydroxylamine; in which the later was prepared by the reduction of p-chloronitrobenzene with zinc powder.

The $\mathrm{pH}$ at maximum extraction of the ligand PCNPPCBHA to the metal vanadium(v) and the ratio of the ligand: metal, were determined.
\end{abstract}

Keywords : Spectrophotometric determination, $\operatorname{Vanadium}(V), p$ - chloro - $N$ - phenyl - $p$ - chloro-benzohydroxamic acid.

\section{Introduction}

Hydroxamic acid have been known since 1869 with the discovery of oxalohydroxamic acid by Lossen (Rappoport \& Liebman 2009) .Dispite this, researches on these compounds were lacking until the1980,after which an enormous amount of information has accumulated with respect to their biomedical applications, synthesis, determination of their metal complexes(Mamion.et al . 2004), their pharmaceutical (Musser et al .1990) and industrial applications(Odake et al.1991), so the chemistry of hydroxamic acid has received considerable attention (Miller 1989),particularly important is their role as siderphores, as well as a model system for natural siderphores (Matzanke et al. 1989).

The ability of hydroxamic acids to form stable transition metal complexes is the basis of their usefulness as an analytical reagent; this is the reason why hydroxamic acids have been used as chelating agents for determination of metals in samples of environmental and industrial importance (Rasuljan et al .1996).

The colored and stable solutions of these metal complexes often provide spectrophotometric methods for determination of several metal ions. Hydroxamic acids having the bidentate functional grouping fulfill the basic requirements of complex formation with metal ions and, therefore form an important family of chelating agents . The complex formation usually takes place with the replacement of the hydroxylamine hydrogen by the metal ion and ring closure through the carbon oxygen as shown below:<smiles>[R]C(=O)NO</smiles>
$+\mathrm{M}^{\mathrm{n}+} \rightleftharpoons$<smiles>[R]c1non1CC1CCCC1</smiles>

\section{Experimental}

All chemicals used were AnalaR grade. All solutions were prepared according to the usual analytical procedures. using distilled water.

A series of buffer solutions ranging from $\mathrm{pH} 1.0$ to $\mathrm{pH} 7.0$ were prepared from a mixture of $0.2 \mathrm{M}$ hydrochloric acid and $0.2 \mathrm{M}$ potassium chloride in different proportions ; and also a mixture of $0.2 \mathrm{M}$ acetic acid and $0.2 \mathrm{M}$ sodium acetate in different proportions.

2.1. Synthesis of p-Chloro-ß -phenyl hydroxylamine (Vogel 1951)

p-chloro- B-phenyl hydroxylamine was prepared by reduction of 0.4 mole p-chloronitrobenzene with 0.9 mole zinc powder in present of 0.4 mole of ammonium chloride at temperature of $55^{\circ} \mathrm{C}$. The products were recrystallized from petroleum benzene.<smiles>O=[N+]([O-])c1ccc(Cl)cc1</smiles>

2.2. Synthesis of the ligand $\mathbf{p}-$ chloro $-\mathbf{N}-$ phenyl $-\mathbf{p}-$ chloro- benzohydroxamic acid ( PCNPPCBHA) (Usha \& Tandon 1967) :

The ligand PCNPPCBHA was prepared by the coupling of 0.1 mole p-chlorobenzoyle chloride (dissolved in diethyl ether) and 
0.1 mole of freshly prepared p-chloro- $\beta$-phenyl hydroxylamine (dissolved in diethyl ether) at temperature of $0^{\circ} \mathrm{C}$ and in present of 0.2 mole sodium hydrogen carbonate. The product was recrystallized from a mixture of benzene and petroleum ether (1:1).<smiles>CCCCNC(=O)OCc1ccc(C(=O)Cl)cc1</smiles><smiles>O=C(Nc1ccc(Cl)cc1)c1ccc(Cl)cc1</smiles>

2.3. Extraction and spectrophotometric determination of vanadium $(\mathbf{V})$ : (determination of the $\mathrm{pH}$ at maximum extraction):

$5 \mathrm{~cm}^{3}$ portions of $100 \mathrm{ppm}$ vanadium solution ((ammonium Meta vandate $\mathrm{NH}_{4} \mathrm{VO}_{3}$. A.R.)) were pipetted into a series of $25 \mathrm{~cm}^{3}$ volumetric flasks and completed to the mark with acetate buffer

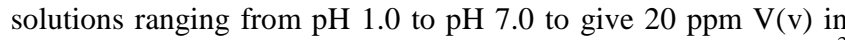
each. The solutions were transferred to a series of $100 \mathrm{~cm}^{3}$ seperatory funnels; few drops of $0.001 \mathrm{M}$ potassium permanganate were added to each till the solution became faint pink color.

$25 \mathrm{~cm}^{3}$ of $0.02 \mathrm{M}$ PCNPPCBHA in chloroform were added to each seperatory funnel and the mixture were shacked gently for two minutes ; the layers were allowed to separate; (I) The organic layer ( lower phase) and (II) The aqueous layer (upper phase). The aqueous layers were taken for further analysis to determine the $\mathrm{pH}$ at maximum extraction.

\subsection{Analysis of the aqueous layer by spectrophotometric procedure (Abdalla, 1980, Ryan 1960):}

The standard ((calibration curve)) for vanadium(v) and the sample ((aqueous layer)) were carried out at the same time for spectrophotometric procedure. Results are shown in Table (6) and (7) and represented graphically in figure (1).

\section{Results and discussion}

The synthesized ligand p-chloro-N-Phenyl-p-chloro benzohydroxamic acid ( PCNPPCBHA) was identified by its melting point table (1) ; infra -red spectroscopy table (2) appendix (A) ; ultra- violet absorption in 95\% ethyl alcohol table (3) appendix (B); elemental analysis of its nitrogen (Abdalla, 1992) and chlorine ( Openshow1995) contents table (4) and table(5) and its reactions towards acidic solutions of vanadium(v) and iron (III) to give respectively ; violet and blood- red colored complexes in the chloroform layers.

Table 1: The Melting Point of the Ligand PCNPPCBHA Using Metteler Melting Point Determination Apparatus.

\begin{tabular}{ll}
\hline & Found \\
\hline Melting point of PCNPPCBHA in ${ }^{\circ} \mathrm{C}$ & $158-159$ \\
\hline
\end{tabular}

Table 2: Characteristic Functional Groups of the Ligand PCNPPCBHA in Nujol Using Infra - Red Spectrophotometer; Perkin Elmer Model 1330.

\begin{tabular}{llllll}
\hline Functional group & $\mathrm{O}-\mathrm{H}$ & $\mathrm{C}=\mathrm{O}$ & $\mathrm{C}-\mathrm{N}$ & $\mathrm{N}-\mathrm{O}$ & $\mathrm{C}-\mathrm{Cl}$ \\
\hline Found in $\mathrm{cm}^{-1}$ & 3185 & 1620 & 1370 & 825 & 720 \\
\hline
\end{tabular}

Table 3: Maximum Absorption of the Ligand PCNPPCBHA In 95\% Ethyl Alcohol Using UV/Vis Spectrophotometer; Perkin Elmer 550S.

\begin{tabular}{lcc}
\hline Ligand & Wave length in $\mathrm{nm}$ & \\
\hline \multirow{2}{*}{ PCNPPCBHA } & $\pi-\pi^{*}$ transition of $\mathrm{C}=\mathrm{O}$ & Aryl ring \\
& 205 & 233 \\
\hline
\end{tabular}

Table 4: Nitrogen Content of The Ligand PCNPPCBHA Using Kjeldhal's Method (Abdalla, 1992)

\begin{tabular}{ccc}
\hline Percentage nitrogen & Calculated & Found \\
\hline$\% \mathrm{~N}$ & 4.96 & 5.02 \\
\hline
\end{tabular}

Table 5: Chlorine Content of the Ligand PCNPPCBHA Using Folhard's Method (Openshow1995).

\begin{tabular}{ccl}
\hline Percentage Chlorine & Calculated & Found \\
\hline$\% \mathrm{Cl}$ & 25.13 & 25.2 \\
\hline
\end{tabular}

Table 6: Absorbance of the Standard Solutions for the Calibration Curve of Vanadium(v) at $\lambda 520 \mathrm{Nm}$

\begin{tabular}{ccc}
\hline Concentration of Vanadium $(\mathrm{V})$ in ppm & Medium & Absorbance \\
\hline 1 & $5 \mathrm{M} \mathrm{HCl}$ & 0.084 \\
2 & $"$ & 0.175 \\
3 & $"$ & 0.259 \\
4 & $"$ & 0.348 \\
5 & $"$ & 0.429 \\
\hline
\end{tabular}

Table 7: Absorbance of the Aqueous Layer from the Extraction of Vanadium (v) With PCNPPCBHA.

\begin{tabular}{lc}
\hline $\mathrm{pH}$ & Absorbance at $\lambda 520 \mathrm{~nm}$ \\
\hline 1 & 0.081 \\
2 & 0.080 \\
3 & 0.073 \\
4 & 0.093 \\
5 & 0.099 \\
6 & 0.089 \\
7 & 0.091 \\
\hline
\end{tabular}

* $\mathrm{pH}$ at maximum extraction implies the lowest value of the of the absorb ance i.e. at $\mathrm{pH}=3.00$

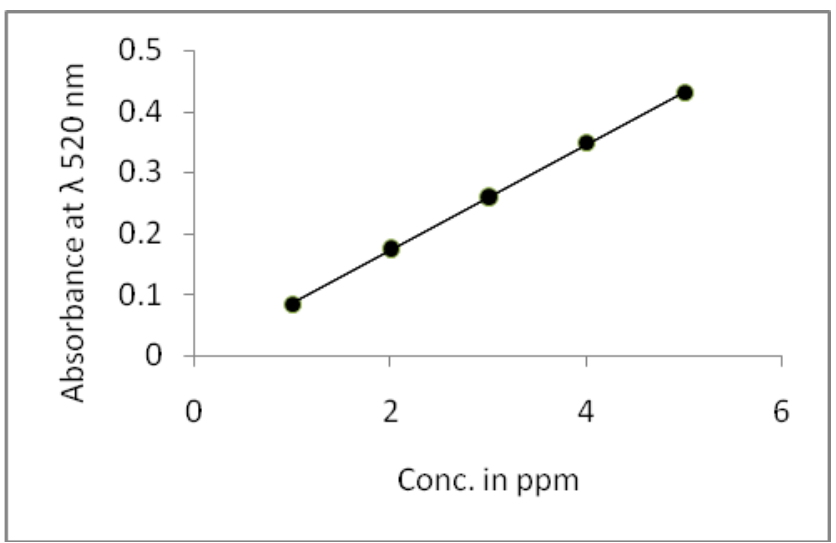

Fig.1: Calibration curve of V (v) for extraction with PCNPPCBHA

Spectrophotometric studies on Vanadium(v) p-chloro-N- phenyl - p-chlorobenzohydroxamic acid complex:

I) Continuous Variation Method:

The composition of Vanadium (v) - PCNPPCBHA complexes was determined by application of the continuous variation method (Job 1928, Warren et al. 1941).Results are shown in Table (8) and represented graphically in figure (2). The blank used was chloroform.

Table 8: Continuous Variation Method for Vanadium (v) - PCNPPCBHA System

\begin{tabular}{lrrrrrrr}
\hline Solution & 1 & 2 & 3 & 4 & 5 & 6 & 7 \\
\hline $\begin{array}{l}\text { Vol.of } \mathrm{V}(\mathrm{v}) 5 \times 10^{-3} \text { in } \\
\mathrm{cm}^{3}\end{array}$ & 2 & 3 & 4 & 5 & 6 & 7 & 8 \\
$\begin{array}{l}\text { Vol. of Acetate } \mathrm{pH} 3 \\
\text { in } \mathrm{cm}^{3}\end{array}$ & 2 & 2 & 2 & 2 & 2 & 2 & 2 \\
$\begin{array}{l}\text { Vol. of Dist. } \mathrm{H}_{2} \mathrm{O} \\
\text { incm }\end{array}$ & 6 & 5 & 4 & 3 & 2 & 1 & 0 \\
$\begin{array}{l}\text { Vol. of ligand } 5 \times 10^{-3} \\
\text { in } \mathrm{cm}^{3}\end{array}$ & 8 & 7 & 6 & 5 & 4 & 3 & 2 \\
$\begin{array}{l}\text { Vol. of chloroform } \\
\text { added to the ligand } \\
\text { before added to the } \\
\text { metal in cm } \\
\quad \mathrm{M}\end{array}$ & 2 & 3 & 4 & 5 & 6 & 7 & 8 \\
$\begin{array}{l}\mathrm{M}+\mathrm{L} \\
\begin{array}{l}\text { Absorbance at } \lambda \\
520 \mathrm{~nm}\end{array}\end{array}$ & 0.20 & 0.30 & 0.40 & 0.50 & 0.60 & 0.70 & 0.80 \\
\end{tabular}




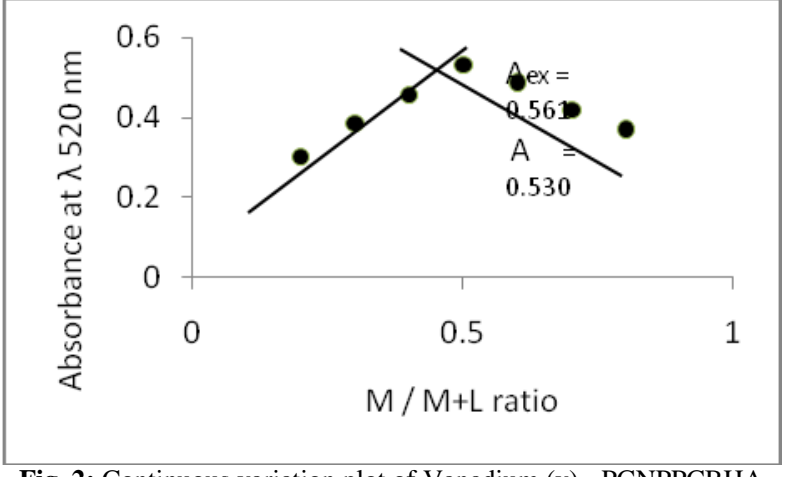

Fig. 2: Continuous variation plot of Vanadium (v) - PCNPPCBHA

II) Slope Ratio Method :

The ratio of the metal Vanadium (v) to the ligand PCNPPCBHA was determined by application of the slope ratio method (Harvey \& Manning 1952) which was found 1:1. Results are shown in table (9) and represented graphically in figure (3).

III) Calibration Curve of Vanadium (v) - PCNPPCBHA system: A standard calibration curve of Vanadium(v)-PCNPPCBHA system was carried out against chloroform as blank. Results are shown in table (10) and represented graphically in figure (4).

Table 9: Slope - Ratio Method for Vanadium (V) - PCNPPCBHA System. Set (A):

\begin{tabular}{|c|c|c|c|c|c|c|}
\hline Solution & 1 & 2 & 3 & 4 & 5 & 6 \\
\hline $\begin{array}{l}\text { Vol. of } \mathrm{V}(\mathrm{V}) \\
5 \times 10^{-3} \mathrm{in}^{3} \mathrm{~cm}^{3}\end{array}$ & 1 & 2 & 3 & 4 & 5 & 6 \\
\hline $\begin{array}{l}\text { Vol. of Acetate } \mathrm{pH} 3 \\
\text { in } \mathrm{cm}^{3}\end{array}$ & 3 & 3 & 3 & 3 & 3 & 3 \\
\hline $\begin{array}{l}\text { Vol. of Dist. } \mathrm{H}_{2} \mathrm{O} \\
\text { in } \mathrm{cm}^{3}\end{array}$ & 6 & 5 & 4 & 3 & 2 & 1 \\
\hline $\begin{array}{l}\text { Vol. of ligand } \\
5 \times 10^{-3} \mathrm{in}^{3}\end{array}$ & 5 & 5 & 5 & 5 & 5 & 5 \\
\hline $\begin{array}{l}\text { Vol. of chloroform } \\
\text { added to the ligand } \\
\text { before added to the } \\
\text { metal in } \mathrm{cm}^{3}\end{array}$ & 5 & 5 & 5 & 5 & 5 & 5 \\
\hline$[\mathrm{V}(\mathrm{V})] \times 10^{-3} \mathrm{M}$ & 0.50 & 1.00 & 1.50 & 2.00 & 2.50 & 3.00 \\
\hline $\begin{array}{l}\text { Absorbance at } \\
\lambda 520 \mathrm{~nm}\end{array}$ & 0.243 & 0.255 & 0.274 & 0.304 & 0.315 & 0.331 \\
\hline
\end{tabular}

Set (B):

\begin{tabular}{lllllll}
\hline Solution & 1 & 2 & 3 & 4 & 5 & 6 \\
\hline Vol,
\end{tabular}

Vol. of $\mathrm{V}(\mathrm{V})$

$5 \times 10^{-3}$ in $\mathrm{cm}^{3}$

$\begin{array}{llllll}5 & 5 & 5 & 5 & 5 & 5\end{array}$

Vol. of Acetate $\mathrm{pH} 3$

in $\mathrm{cm}^{3}$

Vol. of Dist. $\mathrm{H}_{2} \mathrm{O}$

in $\mathrm{cm}^{3}$

Vol. of ligand

$5 \times 10^{-3}$ in $\mathrm{cm}^{3}$

Vol. of chloroform

added to the ligand

before added to the

metal in $\mathrm{cm}^{3}$

[PCNPPCBHA]

$\mathrm{x}^{-3} \mathrm{M}$

3

$3 \quad 3$

2

1

(1)

9

Absorbance at

$\lambda 520 \mathrm{~nm}$

$\begin{array}{llllll}0.50 & 1.00 & 1.50 & 2.00 & 2.50 & 3.00\end{array}$

$\begin{array}{llllll}0.218 & 0.234 & 0.255 & 0.275 & 0.304 & 0.325\end{array}$

Table 10: Calibration Curve for Vanadium (v)- PCNPPCBHA System.

\begin{tabular}{llllll}
\hline Solution & 1 & 2 & 3 & 4 & 5 \\
\hline $\begin{array}{l}\text { Vol. of } \mathrm{V}(\mathrm{V}) 5 \times 10^{-3} \\
\text { in } \mathrm{cm}^{3}\end{array}$ & 1 & 2 & 3 & 4 & 5 \\
$\begin{array}{l}\text { Vol. of Acetate } \mathrm{pH} 3 \\
\text { in } \mathrm{cm}^{3}\end{array}$ & 5 & 5 & 5 & 5 & 5 \\
$\begin{array}{l}\text { Vol. of Dist. } \mathrm{H}_{2} \mathrm{O} \\
\text { in } \mathrm{cm}^{3}\end{array}$ & 4 & 3 & 2 & 1 & 0 \\
$\begin{array}{l}\text { Vol. of ligand } 5 \times 10^{-3} \\
\text { in } \mathrm{cm}^{3}\end{array}$ & 10 & 10 & 10 & 10 & 10 \\
$\begin{array}{l}\text { [V(V)] } \times 10^{-3} \mathrm{M} \\
\begin{array}{l}\text { Absorbance at } \\
\lambda 520 \mathrm{~nm}\end{array}\end{array}$ & 0.50 & 1.00 & 1.50 & 2.00 & 2.50 \\
\hline
\end{tabular}

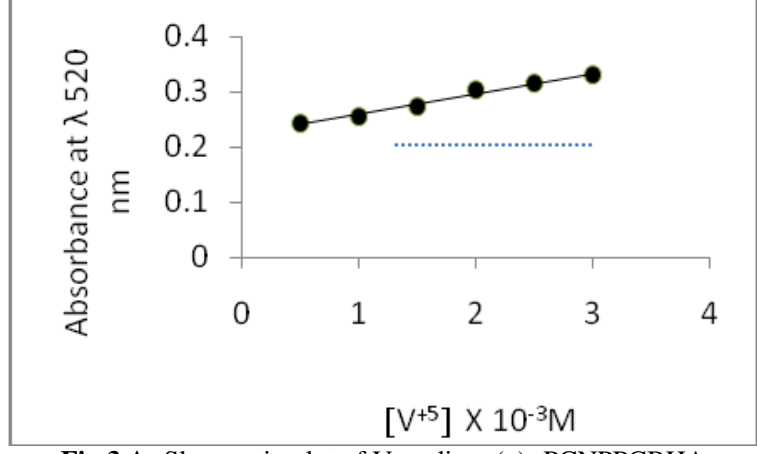

Fig.3 A: Slope ratio plot of Vanadium (v) -PCNPPCBHA

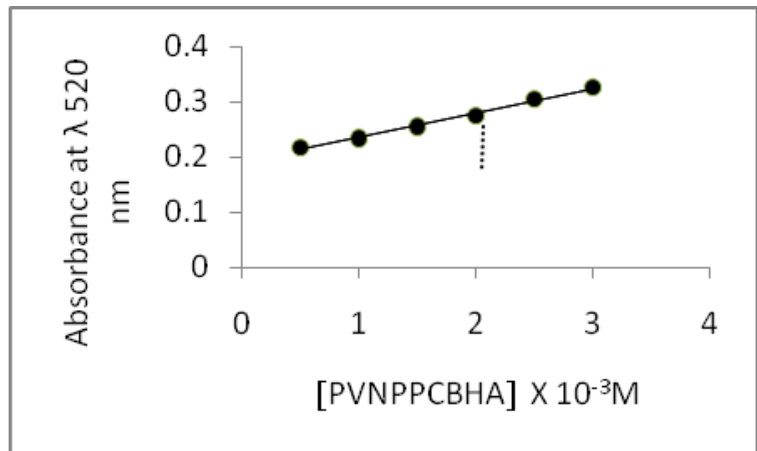

Fig.3 B : Slope ratio plot of Vanadium (v) -PCNPPCBHA

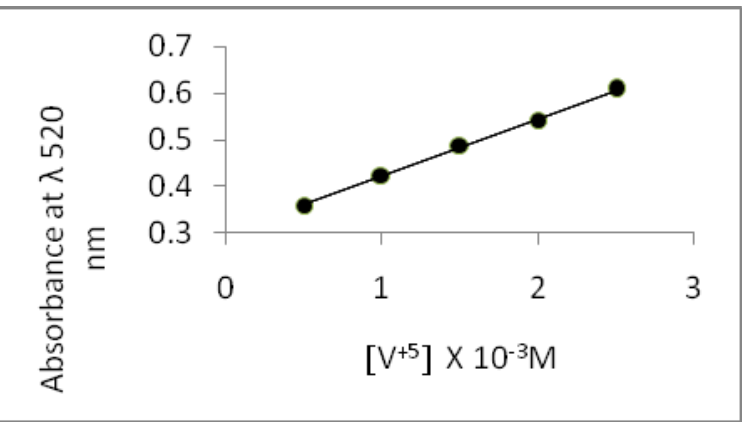

Fig. 4 : Calibration curve for Vanadium (v) -PCNPPCBHA system

\section{Synthesis of the Ligand:}

The ligand PCNPPCBHA was prepared by a coupling reaction which took place under ether process (Usha \& Tandon 1967 ) which is favored over the aqueous process (Tandon \& Bhattacharya 1962) due to the relative purity of the product obtained. The use of sodium hydrogen carbonate in the coupling reaction is to keep the coupling medium slightly alkaline ; also it serves to neutralize hydrochloric acid evolved throughout the reaction. The infra- red spectroscopy for the ligand reveals the absorbance of the most important characteristic functional groups ((Table (2)appendix (A) )) such as $\mathrm{O}-\mathrm{H}$ at $3185 \mathrm{~cm}^{-1}$, the lower shift of

$\mathrm{O}-\mathrm{H}$ instead of $3190 \mathrm{~cm}^{-1}$ (Agrawal 1967) is due to the intra molecular hydrogen bonding of the type $-\mathrm{OH} . . . \mathrm{C}=\mathrm{O}$.

The ultra- violet spectra of the ligand reveal two absorption

maxima $\left(\lambda_{\max }\right)$ when dissolved in $95 \%$ ethyl alcohol; The first band absorbs at $233 \mathrm{~nm}$ referring to the absorption due to the benzene ring and the other band absorbs at $205 \mathrm{~nm}$ referring to the absorption due $\pi-\pi^{*}$ transition of the carbonyl group $(\mathrm{C}=\mathrm{O})$ The substitution of the chloride at the para-position of the two phenyl rings to the parent acid decreases the absorption band due to the carbonyl $\pi-\pi^{*}$ transition when compared with the parent acid alone (Bowie et al .1969).

p-Chloro- $\beta$-phenyl hydroxylamine which is needed for the synthesis of the ligand is an intermediate and of low stability which decompose upon staying for a long time; so it must be freshly prepared and recrystallized for the coupling reaction. 
Calculation of the stability constant for Vanadium (V) PCNPPCBHA complex (Korthoff 1963):

The formation (stability) constant can be determined by job's method.

$$
\begin{gathered}
\mathrm{V}^{+5}+\text { PCNPPCBHA } \leftrightarrow[\mathrm{V}-\text { PCNPPCBHA }]^{+5} \\
\mathrm{~K}_{\mathrm{f}}=\frac{[\mathrm{V}-\text { PCNPPCBHA }]^{+5}}{\left[\mathrm{~V}^{+5}\right][\text { PCNPPCBHA }]}
\end{gathered}
$$

The concentration of the species $[\mathrm{V}-\mathrm{PCNPPCBHA}]^{+5} ; \mathrm{V}^{+5}$ and [PCNPPCBHA $]^{\circ}$ should be calculated from the maximum absorbance (A) observed in job's curve figure (2).

$\mathrm{A}_{520 \mathrm{~nm}}=0.530$

Volume of $\mathrm{V}^{+5}=5 \mathrm{~cm}^{3}$ From table (8)

Volume of PCNPPCBHA $=5 \mathrm{~cm}^{3}$

$\left\lfloor\mathrm{C}_{\mathrm{V}^{+5}}\right\rfloor=\left\lfloor\mathrm{V}^{+5}\right\rfloor+[\mathrm{V}-\mathrm{PCNPPCBHA}]^{+5}$

$\therefore\left[\mathrm{V}^{+5}\right]=\left[\mathrm{C}_{\mathrm{V}^{+5}}-[\mathrm{V}-\mathrm{PCNPPCBHA}]^{+5}\right]$

Also ; $\quad \mathrm{C}_{\mathrm{PCNPPCBHA}}=[\mathrm{PCNPPCBHA}]+[\mathrm{V}-\mathrm{PCNPPCBHA}]^{+5}$

$\therefore[\mathrm{PCNPPCBHA}]=\mathrm{C}_{\text {PCNPPBHA }}-[\mathrm{V}-\mathrm{PCNPPCBHA}]^{+5}$

$\mathrm{C}_{\mathrm{V}^{+5}}=\frac{0.005 \mathrm{X} 5}{10}=0.025 \mathrm{M}$

$\mathrm{C}_{\text {PCNPPCBHA }}=\frac{0.005 \mathrm{X} 5}{10}=0.025 \mathrm{M}$

$A_{\text {ex }}$ Is the extrapolated absorbance i.e. the absorbance which

would be observed if the complex didn't dissociate at all. When this happens the equilibrium concentration of the complex

$[\mathrm{V} \text { - PCNPPCBHA }]^{+5}$ Would be equal to the analytical

Concentration of the vanadium $\mathrm{C}_{\mathrm{V}^{+5}}$.

From job's curve figure (2):

$\mathrm{A}_{\mathrm{ex}}=0.561$ at $\lambda 520 \mathrm{~nm}$

$[\mathrm{V}-\mathrm{PCNPPCBHA}]^{+5}=\mathrm{C}_{\mathrm{V}^{+5}}$

$\mathrm{A}_{\mathrm{ex}}=[\mathrm{V}-\mathrm{PCNPPCBHA}]^{+5}=\mathrm{C}_{\mathrm{V}^{+5}}$

since $\mathrm{A}=[\mathrm{V}-\mathrm{PCNPPCBHA}]^{+5}$

therefor, $\quad \frac{\mathrm{A}}{\mathrm{A}_{\mathrm{ex}}}=\frac{[\mathrm{V}-\mathrm{PCNPPCBHA}]^{+5}}{\mathrm{C}_{\mathrm{V}^{+5}}}$

$\therefore[\mathrm{V}-\mathrm{PCNPPCBHA}]^{+5}=\frac{\mathrm{A}}{\mathrm{A}_{\mathrm{ex}}} \cdot \mathrm{C}_{\mathrm{V}^{+5}}$

Substituting equation (2) and (3) in equation (1) we get:

$\mathrm{K}_{\mathrm{f}}=\frac{[\mathrm{V}-\mathrm{PCNPPCBHA}]^{+5}}{\left(\mathrm{C}_{\mathrm{V}^{+5}}-\left[\mathrm{V}-\mathrm{PCNPPCBHA}^{+5}\right) \cdot\left(\mathrm{C}_{\text {PCNPPCBHA }}-[\mathrm{V}-\text { PCNPPCBHA }]^{+5}\right)\right.}$

Substituting equation (4) in the above equation we get :

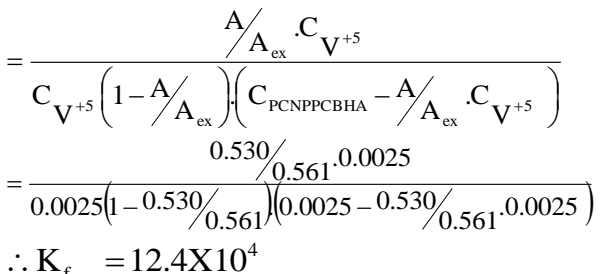

\section{References}

[1] Abdalla, H.A/aziz. (1980), Ph.D thesis, University of Sal-ford, England.

[2] Abdalla, H.H. (1992), M.SC. Thesis, Faculty. Of Science, University of Khartoum. Sudan.

[3] Agrawal, Y. K. (1967), J.Chem. And Eng.data, 22, 175.

[4] Bowie, H. J; Hearn .W .M, and Ward, D.A. (1969), Aust. J.Chem., 22, 175.

[5] Harvey, A. E, and Manning, D. L (1952). J.Am.Chem.Soc., Vol. 74 4744. http://dx.doi.org/10.1021/ja01139a005.

[6] Job (1928), Ann. Chem. Paris, 9, 113.

[7] Korthoff, I. M. (1963), J.Am.Chem.Soc., 25, 315.
[8] Mamion.C.J, Griffith.D and Nolan. K.B Eur.J.Inorg.Chem. 2004 3003 .

[9] Matzanke B.F., Mueller G. and Raymond K.N. (1989) "Siderophore medicated Iron Transport; Chemistry, Biology and Physical Properties in Physical Bioinorganic Chemistry " VCH Publishers NewYork.

[10]Miller M.J. (1989) Chem.Rev.89, 1536.

[11] Musser. J.H, Kreft A.F., Bender R.H.W. (1990) J.Med.Chem.33, 240 http://dx.doi.org/10.1021/jm00163a039.

[12]Odake- Sh., Okayama T. and Obata M. (1991) Chem.Pham.Bull .39, 1489.

[13] Openshow, H. T., (1995) " A laboratory Manual of Qualitative Organic Analysis"Cambridge University Press, 3rd ed.

[14]Rappoport .Z and Liebman.J.F(2009) "The chemistry of hy-droxyla mines, oximes and hydroxamic acids " John Wiley and sons ltd,, part 1,187 .

[15]Rasuljan M., Jan N. and Khwaja M.A. (1996) J.Chem.Soc.Pak. 18(2), 101.

[16]Ryan, D. E. (1960) Analyst, Vol. 785, P 569 http://dx.doi.org/10.1039/an9608500569

[17] Tandon. S. G, and Bhattacharya, S, (1962), J.Chem. And Eng.data, 7, 553. http://dx.doi.org/10.1021/je60015a036.

[18]Usha, P. Tandon. S.G (1967), J. of Chem. and Eng.data, 12, (1), 143. http://dx.doi.org/10.1021/je60032a046.

[19] Vogel, A.I., (1951), "A text book of practical organic chemistry ", Longmans,London 2nd. Ed.

[20]Warren, C. Vosburgh and Gerald R. Cooper (1941), J. of Am.Chem. Soc., 63, 437. http://dx.doi.org/10.1021/ja01847a025. 